\title{
Effect of G6PD Activity, Mediterranean Mutation and Some Biomarkers on Patients with Diabetes Mellitus
}

\author{
Abdulqader Wael Rasheid ${ }^{1}$, Firas Taher Maher ${ }^{1}$, Akeel Hussein Al-Aisse ${ }^{2}$, Adnan Fadhel Nasseef ${ }^{2}$ \\ ${ }^{1}$ Department of Chemistry, College of Science, University of Tikrit, Tikrit, Iraq \\ ${ }^{2}$ Department of Biology, College of Science, University of Tikrit, Tikrit, Iraq
}

Email address:

www.chemistbird1@yahoo.com (A.W. Rashid),www.chemistbird11@gmail.com (F. T. Maher), www.akalassie09@yahoo.com. (A.H. Al-Aisse),www.Adnanmolecular1@gmail.com (A. F. Nasseef)

\section{To cite this article:}

Abdulqader Wael Rasheid, Firas Taher Maher, Akeel Hussein Al-Aisse, Adnan Fadhel Nasseef. Effect of G6PD Activity, Mediterranean Mutation and Some Biomarkers on Patients with Diabetes Mellitus. Advances in Biochemistry. Vol. 9, No. 3, 2021 , pp. 82-89.

doi: 10.11648/j.ab.20210903.17

Received: July 19, 2021; Accepted: August 7, 2021; Published: August 31, 2021

\begin{abstract}
Diabetes mellitus is a metabolic disease belongs to a group of disparate diseases clinically and genetically characterized by increased blood sugar (hyperglycemia) as a result of defect in insulin metabolism. Glucose-6-Phosphate Dehydrogenase (G6PD) (Oxidoreductase, EC 1.1.1.1-49) is one of the most important enzymes of the metabolite, the main enzyme and the key to the Pentose phosphate path way. Unsuitable control of blood glucose decreases G6PD activity and increases diabetes mellitus complications. the This study evaluated effect of Mediterranean mutation which causes decrease G6PD activity on diabetes patients and evaluated the difference of G6PD activity among diabetic and non-diabetic patients, and the impact of hyperglycemia on the G6PD activity and different in G6PD activity in six and age and relation between Calcium and Magnesium with G6PD activity and Mediterranean mutation and found correlative coefficient(r) between G6PD activity in Patient and Blood sugar, Calcium, Magnesium and G6PD activity in healthy people. Asixteen diabetic and nondiabetic subjects were selected from patients 8 to 60 years old. Demographic data including gender, age, height, weight, duration of diabetes mellitus, type and duration of treatment, medical history (especially fauvism) were recorded. Blood pressure and body mass index were also measured. One blood sample was taken from each subject and 5 elements including G6PD presence and activity, fasting plasma glucose, plasma Calcium, Magnesium and DNA was extraction from whole blood and then amplified by polymerase chain reaction (PCR) and later subjected to digestion by restriction enzyme MboII to create restriction fragment length polymorphism (RFLP) to enable the detection of mutation that caused G6PD deficiency namely Mediterranean (Med). G6PD activity was significantly higher in non-diabetic subjects $(\mathrm{P}<0.05)$. Within diabetics, G6PD mean activity was significantly higher in non-group $(\mathrm{P}<0.05)$ and in subjects with $\mathrm{BMI}<25(\mathrm{P}<0.05)$. G6PD mean activity was significantly higher in non-diabetics than $(\mathrm{P}<0.01)$ and $\mathrm{Ca}, \mathrm{Mg}$ diabetics patients $(\mathrm{P}<0.05)$ the Med-G6PD mutation in diabetes patient was more in non-diabetes patient, (47) diabetes patient have Med-G6PD (78.3\%) and (15) non diabetes have the mutation $(15 \%)$ and the G6PD activity was significantly higher with Med-G6PD mutation in in diabetes patient $(\mathrm{P}<0.05)$ and non-significantly higher with non-diabetes patient. The Med-G6PD mutation can be used as molecular marker to diagnosis diabetes, Diabetic hyperglycemia may lead to serious complications and decrease G6PD activity. This issue itself aggravates diabetic injury due to inappropriate anti oxidation process. Simultaneous dyslipidemia and obesity may intensify the effect of hyperglycemia and oxidative stress.
\end{abstract}

Keywords: Glucose-6-phosphate Dehydrogenase (G6PD), Diabetes Mellitus, PCR-RFLP, Mediterranean Mutation

\section{Introduction}

Diabetes mellitus is a metabolic disease belongs to a group of disparate diseases clinically and genetically characterized by increased blood sugar hyperglycemia as a result of defect in insulin metabolism [1]. When you don't control the increase blood hyperglycemia diabetes properly, it causes long term damage and imbalances in the different organs of the body and especially the eyes, kidneys, nerves, heart, and blood, diabetes link creates several genetic and 
environmental factors simultaneously [2]. Insulin resistance and lack of insulin secretion are the hallmarks of pathophysiology of diabetes [3].

Glucose-6-Phosphate Dehydrogenase (Oxidoreductase, EC 1.1.1.1-49) is one of the most important enzymes of the metabolite, the main enzyme and the key to the Pentose phosphate path way. It stimulates the process of oxidation of the glucose-6-phosphate (G-6-P) (NADP +) to save the life-producing pathways of many important substances, particularly in red blood cells because they have no other source of NADPH. NADPH produced by the enzyme G6PD has a role Supplemented with the enzyme glutathione peroxidase, which leads to the reduction of oxidative glutatathione (GSSG) and its transformation (GSH), which protects human red blood cells from partial destruction $[4,36]$.

Most of the isoenzyme is produced by replacing one amino acid with another in a chain sequenced by mutations. In three analogues of G6PD: A, G6PD: Mountsinai and G6PD: Santamaria, (G6PD: A) [5, 37]. In a study carried out by a number of researchers, three amino acids were recorded in the peer (G6PD: Vancouver), and in another study that was recorded Amino acid is eliminated in a chain sequenced in the enzyme molecule and produced analog (G6PD: Sunderland) which rarely occurs, and in another study the researchers recorded the abolition of eight Amino acids in one of the isotopes to produce analogues (G6PD: Nara [6, 38]. These studies have shown that enzymatic dysfunction is occurring in the enzyme gene [7, 39].

A large number of isoenzyme and enzymatic variables have been described by biochemical properties and have been identified without genetic mutations. However, other isoenzyme cannot be diagnosed without relying on genetic mutations. To the high accuracy of the diagnosis based on genetic mutations of the isoenzyme determined by the biochemical properties that the mutations give more accurate results [7]. Med-G6PD is one of the most important and common mutations of the enzyme. The mutation produces cytosine $(\mathrm{C})$ to thymine $(\mathrm{T})$ in nucleotide $(563)$ in exon $[6,39$, 40]. Med-G6PD induced the substitution of phenylalanine amino acid instead of serine on site as in figure 1 .

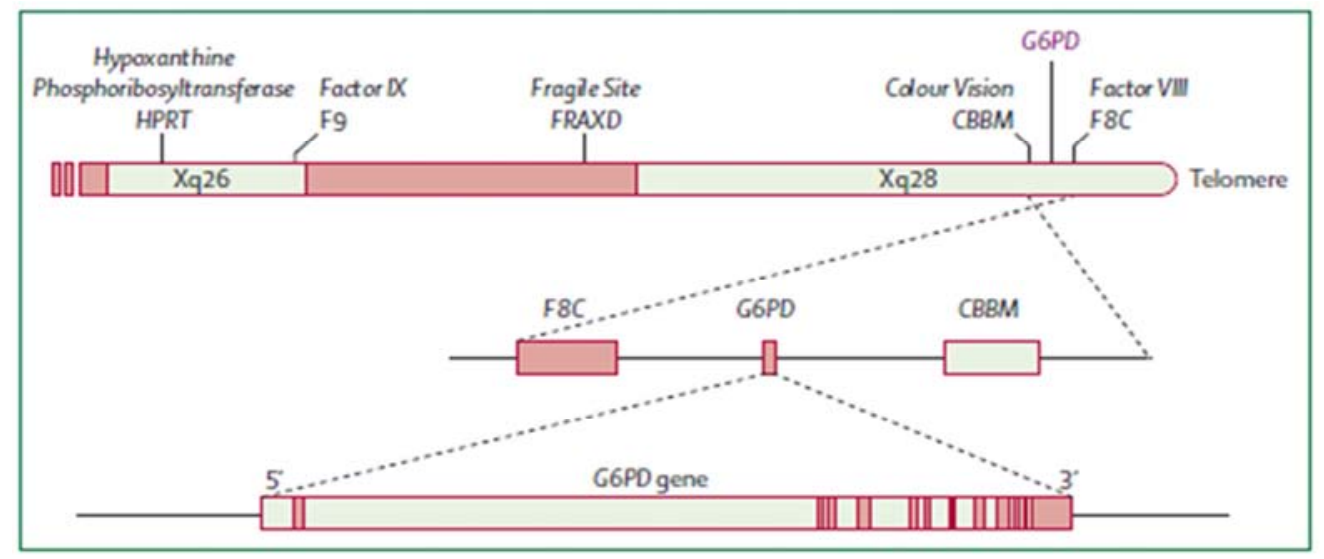

Figure 1. Position of G6PD gene in chromosome X in position 28.

Because of the importance of the enzyme and the presence of mutations in the Mediterranean basin, Iraq this study carried out to estimate the biochemical and genetic variables in diabetes patients.

\section{Experimental}

Biochemical tests: The samples were collected (60) samples of patients 40 male and 20 female, (60) samples of the control group 39 male and 21 female at Salah-Alden, General Hospital in Tikrit for the period from 1/9/2016 to $12 / 1 / 2017$. Age of the participants was between 8 to 69 years. Ten-milliliter disposable plastic syringes were used to draw venous blood from each patient and control and then the samples were left for $20-30$ minutes at $37^{\circ} \mathrm{C}$. The serum was used for the analysis after separation by centrifugation in vitro. In the present study, cholesterol, triglyceride, HDLcholesterol, G6PDH, $\mathrm{Mg}, \mathrm{Ca}$ and Alb. were estimated using cholesterol, triglyceride, HDL-cholesterol, G6PDH, Mg, Ca and Alb. kits form biolabo company (France) Colorimetric method. PCR pre Mix (Bioneer-Korea).

\section{Molecular Study}

DNA was extracted from the blood tissue using Saremi etal method, [8]. DNA concentration was measured by nano drop 2000 in the unit (ng $/ \mu \mathrm{l})$ and purity, to confirm the step extracted DNA was run on $1 \%$ agrose gel.

Lyophilized Primers were re-dissolved with distilled water to be $10 \mathrm{Pmol} / \mu \mathrm{L}$. table 1 .

Table 1. PCR in the G6PD Interaction Primers Used to Detect Gene.

\begin{tabular}{lllll}
\hline Primer & Primer sequences & Length $(\mathbf{p b})$ & Final concentration & Temp $\left({ }^{\circ} \mathbf{C}\right)$ \\
\hline G6PD-6-F & $5^{\prime} \ldots$ CCCCGAAGAGGAATTCAAGGGGGT $\ldots 3^{\prime}$ & 24 & 10 Pmol $/ \mu \mathrm{L}$ & 60.8 \\
G6PD-6-R & $5^{\prime} \ldots$ GAAGAGTAGCCCTCGAGGGTGACT...3' & 24 & $10 \mathrm{Pmol} / \mu \mathrm{L}$ & 58 \\
\hline
\end{tabular}


A mix preparation reaction where PreMix is ready for use, the final volume is completed to $20 \mu \mathrm{L}$ by distilled water. The reaction components were:

Table 2. PCR components.

\begin{tabular}{lll}
\hline Concentration & Volume & Species \\
\hline $20-25 \mathrm{ng} / \mu \mathrm{L}$ & $2 \mu \mathrm{L}$ & DNA Template \\
5 Pico mole & 1 Micro liter & F- primer \\
5 Pico mole & 1 Micro liter & R- Primer \\
- & 2 Micro liter & Premix \\
& Micro liter 14 & Distill water \\
\hline
\end{tabular}

Samples were placed in the device after they were taught and the program adopted by the researchers (Al-Tu'ma. F (Jawad and William M) was activated in the system as follows [9]:

Table 3. PCR programmer.

\begin{tabular}{llll}
\hline $\begin{array}{l}\text { Type of PCR } \\
\text { reaction }\end{array}$ & Temperature $^{\circ} \mathbf{C}$ & Time min & Number of cycles \\
\hline First Denaturation & 94 & 5 & 1 \\
Denaturation & 94 & 1 & \\
Annealing & 58 & 1 & 35 \\
Extension & 72 & 1 & \\
Final Extension & 72 & 5 & 1 \\
\hline
\end{tabular}

Use the MboII to cut the PCR product to detect the Mediterranean mutation in the G6PD gene, according to the Al-Jumaily Essam F. and Al-Temmemy Rana. A method [10]. Table 4 shows the enzyme designation used in this study and its source:

Table 4. Source of the MboII enzyme and its location and its source.

\begin{tabular}{lll}
\hline Name of bacteria of enzyme & Position of cut & Enzyme \\
\hline \multirow{2}{*}{ Moraxella bovic ATCC10900 } & 5 `... GAAGA* ...3 & \multirow{2}{*}{ Mboll } \\
\hline
\end{tabular}

The specificity of the enzyme is exploited with the PCR product to accurately detect a genetic mutation in patients with PCR-RFLP [11]. This was applied in this part of the study. Genetic mutations were detected at sites C563T and C563A for G6PD gene in diabetic patients The steps were carried out as follows: - 10Unit of the enzyme was added to 5 $\mu 1$ of the PCR reaction product and the result was incubated for 4 hours, a period of incubation for partial digestion or (18) hours of incubation period. $(2.5 \%) \mathrm{w} / \mathrm{v}$, and the result was recorded with an E-Graph device.

\section{Result and Discussion}

Table 5 show G6PD activity, levels of $\mathrm{Ca}, \mathrm{Mg}$, cholesterol, HDL-C, VLDL-C, LDL-C, TG, Total protein, Albumin and Globulin in the group of diabetic patients (type I and type II) compared to control group. The results showed a significant decrease in the probability level $(\mathrm{P}<0.05)$ in the rate of efficacy of G6PD in females of the age groups 8-45 years, 45-69 years in patients with type I and II diabetes compared to the control group, and the results showed no significant decrease Probability level $(\mathrm{P}<0.05)$ in the rate of efficacy of G6PD in females in the age group (45-8) in patients with type 1 diabetes compared with patients of type 2 for the same age group and for the age group $(69-45)(\mathrm{P}<0.05)$ at the G6PD efficacy rate in females, The results showed no significant decrease in the level of probability $(\mathrm{P}<0.05)$ in the rate of efficacy of G6PD in females aged 8 to 45 years in patients with type 1 diabetes $(10.218 \pm 0.578)$ compared to the age group 46-69 years. $(9.052 \pm 1.176)$, as well as the no significant difference in G6PD efficacy rate at the probability level $(\mathrm{P}<0.05)$ for male patients of type I and II and control group when comparing the age group 8 to 45 years and the age group 46-69 years. This result agrees with the researchers Cappai G, et. al. [12], and Nkhoma ET, et. al. [13], who found no significant difference in the activity of G6PD in different age groups. Statistical analysis showed a very low significant increase in the rate of enzyme activity for older persons compared to the rest due to the genetic deficiency caused by genetic mutations.

The results showed a significant decrease in the probability level $(\mathrm{P}<0.01)$ in the calcium levels of patients of type II diabetics compared with the control group. This result agrees with a study researcher Rieyadh. et. al, [14] Ameerah M. et. al. [15], Crawford. A et. Al [16], Hamad NA, et. al., [17]. The results showed that there was no significant decrease in the level of calcium for type 2 diabetics compared to others. A study by Levy J, et. al. [18], confirmed that the balance of calcium level in the body is necessary for the work of the secretion of Insulin from beta cells to the at high level of glucose in the blood. The results agree with the study by AL-Sammraie Abdilkarim J. Yehia [19] and Fogh-Andersen N, et. al. [20] found a significant decreased in calcium levels for type1 patients. The reason for the low level of calcium in type 1 diabetic patients compared to type 2 patients was due to the increased calcium salts and the decrease in thyroid activity in type1 patients Compared to patients with type II. the results showed a significant decrease in magnesium concentration of patients compared with Control group, and this agrees with the researchers Fang Linyan, LI Xueping [21], and Sung, CC, Liao, et. al. [22] showed that there was significant decrease in the level of magnesium with diabetes. The decrease in magnesium levels in some patients is due to the nature of the food or to an increase in the amount of magnesium produced by the kidney due to dysfunction in diabetes.

There was a significant increase in the concentration of cholesterol, TG, VLDL-C and LDL at the probability level $(\mathrm{P}<0.001)$ in the serum patients with type 1 diabetes and type II and a significant difference in the concentration of cholesterol at the probability level $(\mathrm{P}<0.05)$ when comparing between type I and II diabetics. High significant decrease of high-density lipoprotein (HDL) for type 1 and type patients compared to control group because diabetes leads to decline metabolism of carbohydrates leads to imbalance in fat metabolism in the body leading to a decrease in the level of high-density lipoproteins [23, 41].

A decrease was not significant at the level of probability $(\mathrm{P}<0.01)$ in total protein concentration of patients of both sexes compared with the control group because of a defect in kidney 
function leads to crash proteins and decay This leads to a high concentration of urea in the body. This result agrees with the study by researcher Salim J. Khalaf [24] and Nanda, R et al. [25] who found that was not significant at the level of probability $(\mathrm{P}<0.01)$ in total protein concentration of patients of both sexes compared with the control group because of a defect in kidney function leads to crash proteins and decay This leads to a high concentration of urea in the body. Statistical analysis of the current results showed a significant decrease in the level of probability $(\mathrm{P}<0.01)$ in the level of albumin for patients with diabetes type I compared with the control group, while there is a decrease significantly for patients with type II compared with the control group. This result agrees with (Ou HY, et al) and (Amal R. Farahan and Walla E. Jassem) [26, 27].

Table 5. G6PD activity in the group of diabetic patients compared to control group by sex and age.

\begin{tabular}{|c|c|c|c|c|c|c|}
\hline & \multicolumn{2}{|c|}{ Control Mean \pm SD } & \multicolumn{2}{|c|}{ Diabetes type I Mean \pm SD } & \multicolumn{2}{|c|}{ Diabetes type II Mean \pm SD } \\
\hline & Male & Female & Male & Female & Male & Female \\
\hline \multicolumn{7}{|c|}{ G6PD activity (IU/gHb) } \\
\hline Age $(8-45$ yrs & $13.8 \pm 0.54$ & $12.857 \pm 0.25$ & $9.750 \pm 0.90$ & $10.218 \pm 0.57$ & $9.610 \pm 0.11$ & $9.760 \pm 0.54$ \\
\hline Age 46-69 yrs & $14.010 \pm 0.12$ & $13.110 \pm 0.15$ & $10.977 \pm 0.86$ & $9.052 \pm 1.17$ & $9.458 \pm 0.40$ & $10.497 \pm 0.83$ \\
\hline Calcium (mg $\backslash \mathrm{dl})$ & $8.92 \pm 1.66$ & $9.558 \pm 0.30$ & $7.524 \pm 0.67$ & $7.524 \pm 0.67$ & $8.917 \pm 0.294$ & $9.653 \pm 0.58$ \\
\hline Magnesium (mgldl) & $1.79 \pm 0.19$ & $1.850 \pm 0.037$ & $1.80 \pm 0.032$ & $1.877 \pm 0.046$ & $1.79 \pm 0.03$ & $1.725 \pm 0.038$ \\
\hline HDL-C (mg/dl) & $59.25 \pm 1.48$ & $41.09 \pm 1.949$ & $42.83 \pm 3.51$ & $36.10 \pm 3.13$ & $36.93 \pm 1.63$ & $37.66 \pm 3.56$ \\
\hline VLDL (mg/dl) & $21.57 \pm 1.57$ & $46.64 \pm 2.79$ & $49.36 \pm 6.54$ & $46.64 \pm 2.79$ & $53.34 \pm 1.61$ & $51.30 \pm 3.95$ \\
\hline LDL (mg/dl) & $115.11 \pm 5.96$ & $102.23 \pm 6.98$ & $183.80 \pm 5.87$ & $152.36 \pm 18.86$ & $177.65 \pm 8.33$ & $175.03 \pm 12.43$ \\
\hline $\mathrm{TG}(\mathrm{mg} / \mathrm{dl})$ & $107.89 \pm 7.86$ & $121.42 \pm 8.99$ & $186.83 \pm 3.21$ & $183.20 \pm 13.9$ & $171.71 \pm 8.06$ & $196.50 \pm 19.7$ \\
\hline Total Protein (mg/dl) & $7.06 \pm 0.17$ & $7.36 \pm 0.23$ & $6.11 \pm 0.46$ & $7.17 \pm 0.0 .32$ & $7.09 \pm 0.18$ & $6.35 \pm 0.35$ \\
\hline Albumin (mg/dl) & $4.26 \pm 0.15$ & $4.00 \pm 0.16$ & $4.47 \pm 0.37$ & $4.66 \pm 0.24$ & $4.58 \pm 0.16$ & $4.48 \pm 0.39$ \\
\hline Globulin (g/dl) & $7.06 \pm 0.17$ & $7.36 \pm 23$ & $6.11 \pm 0.46$ & $7.17 \pm 0.32$ & $7.09 \pm 0.18$ & $6.35 \pm 0.35$ \\
\hline
\end{tabular}

Correlative between the enzyme G6PD and a number of clinical variables in patients with type I and II diabetes and control groups:

To find the relationship between the G6PD and a number of clinical variables in patients with type I, II diabetes and control groups, correlative coefficient (r) was found.

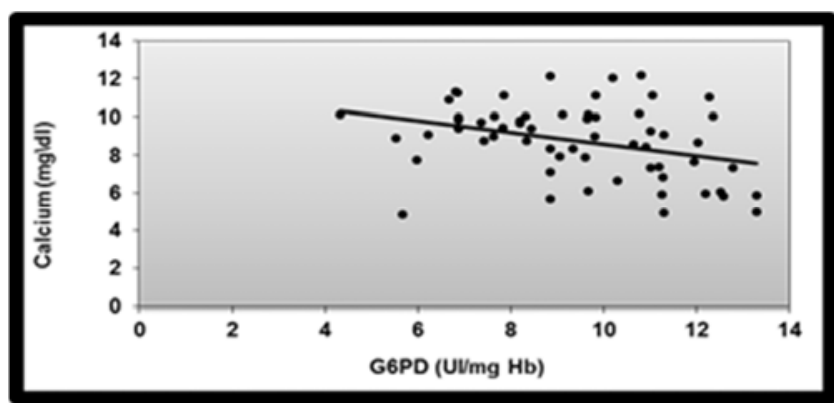

Figure 2. Correlation between G6PD and calcium concentration.

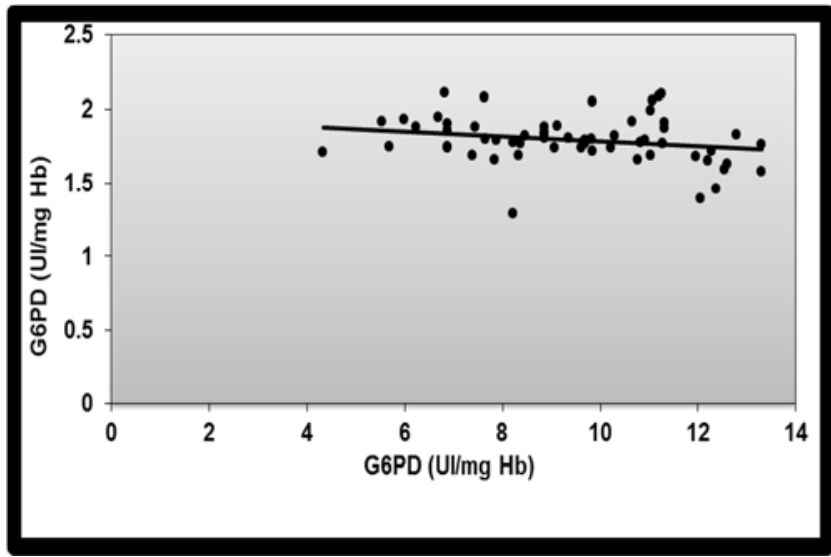

Figure 3. Correlation between G6PD and Control concentration.

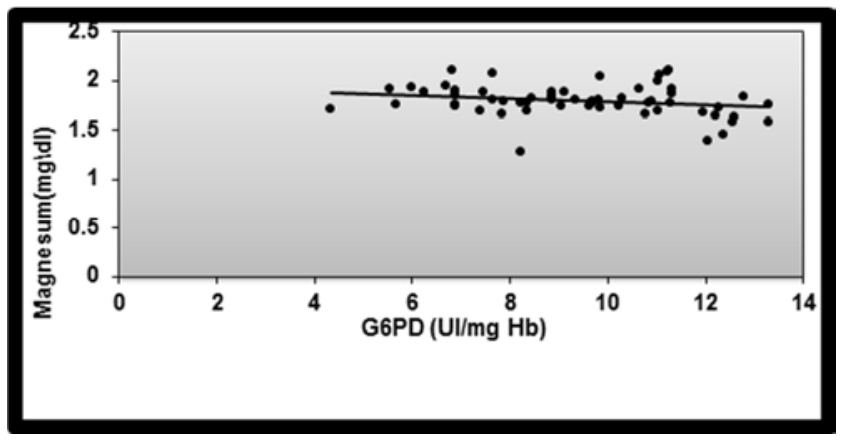

Figure 4. Correlation between G6PD and Magnesium concentration.

Figure 1 shows There is a linear correlation between the decline in the G6PD activity in patients with diabetes type I and II patients, and its activity in the control group, as the value of the correlation coefficient between them (-0.375). This result agrees with the Pinna Antonio et, al. who found low enzyme activity in diabetics compared to control group due to low level of antioxidants for diabetic patients because of metabolic disorder caused by disease [28]. The absence of a linear correlation between low enzyme activity in patients with diabetes type I, II, and the level of concentration of calcium and magnesium, as the value of their correlation coefficient (0.028) and (0.044) respectively. The absence of a linear correlation between low enzyme activity in patients with diabetes type I, II and cholesterol, HDL, LDL, VLDL, TG and Albumin levels. The value of their correlation coefficient $(0.088),(0.1),(0.042),(0.083),(0.083)$ and ($0.099)$ respectively. linear correlation between low enzyme activity in patients with diabetes type I, II, and the level of concentration of Total protein and Globulin the correlation coefficient was 0.361 and 0.295 respectively. 


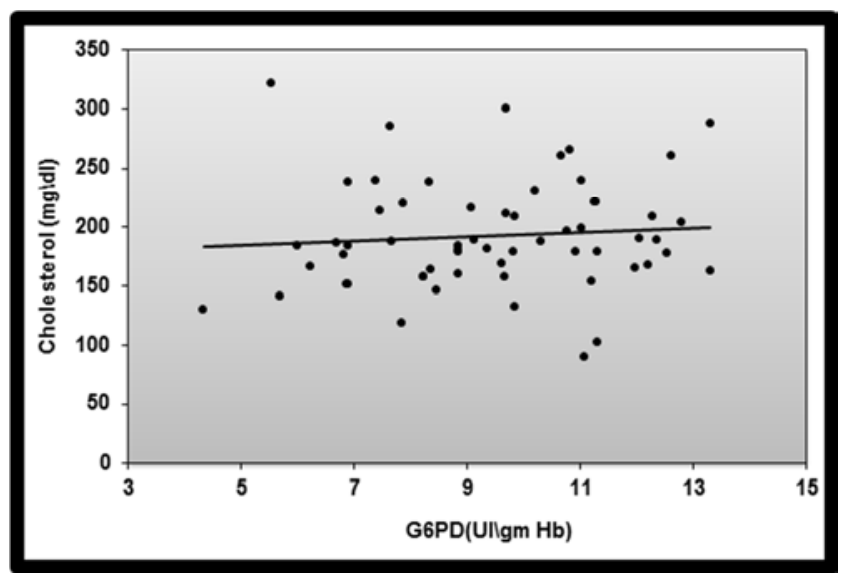

Figure 5. Correlation between G6PD and Cholesterol concentration.

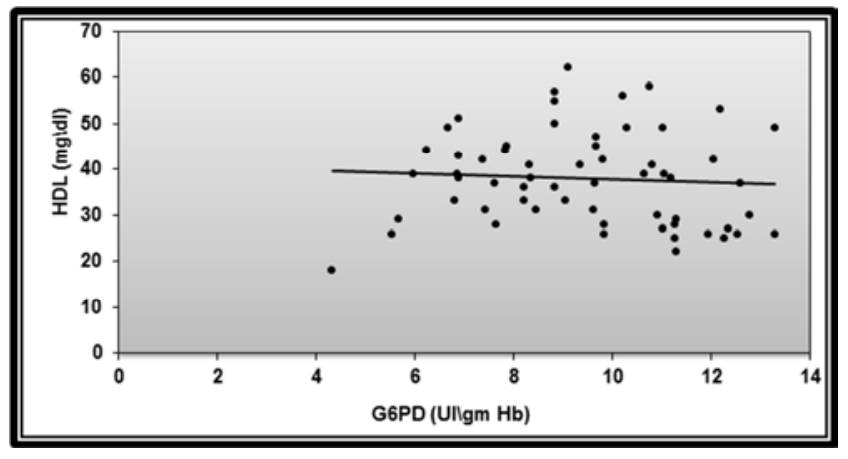

Figure 6. Correlation between G6PD and HDL concentration.

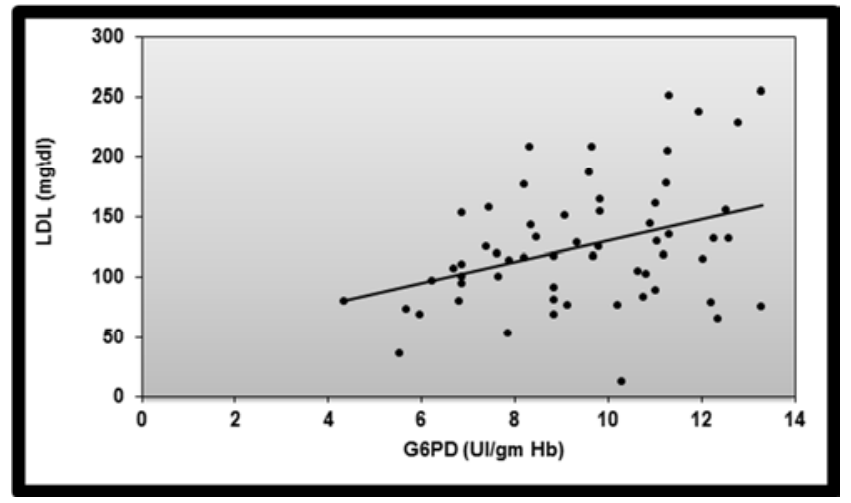

Figure 7. Correlation between G6PD and LDL concentration.

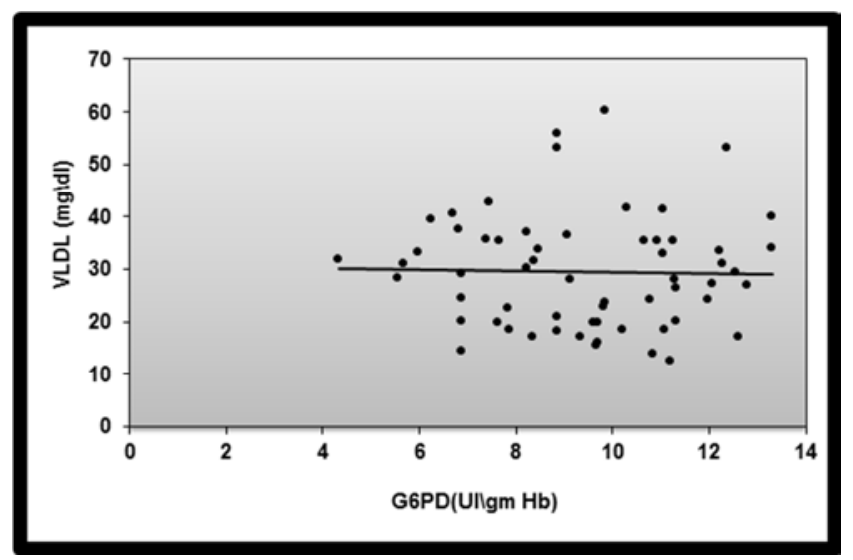

Figure 8. Correlation between G6PD and VLDL concentration.

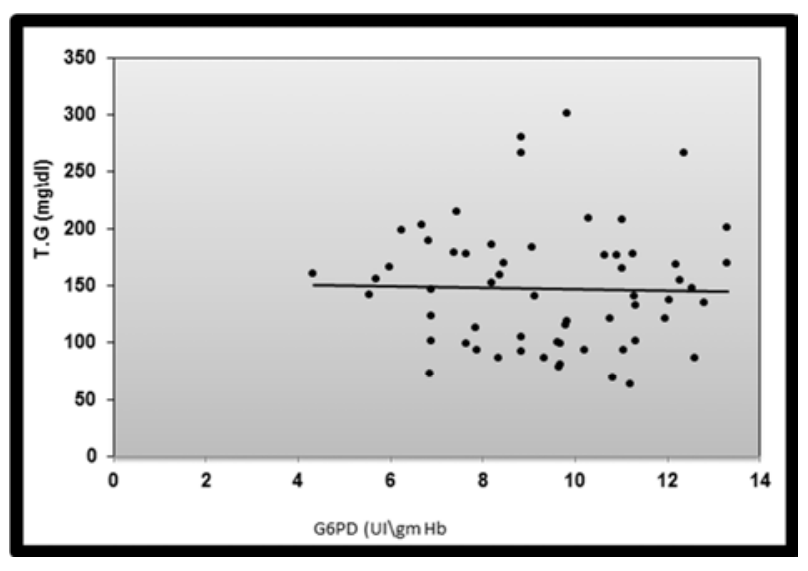

Figure 9. Correlation between G6PD and TG concentration.

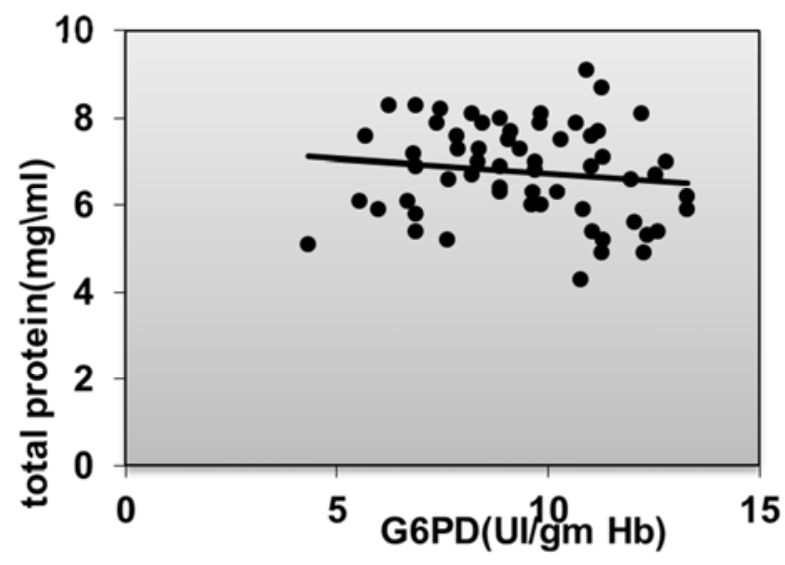

Figure 10. Correlation between G6PD and Total protein concentration.

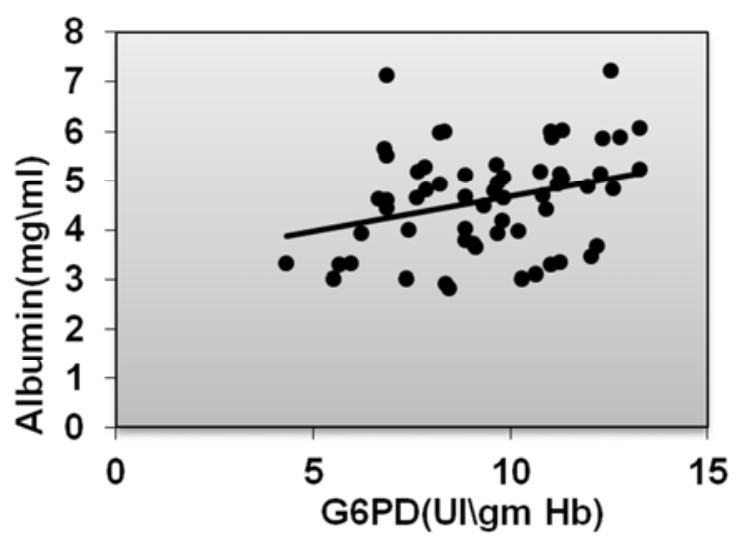

Figure 11. Correlation between G6PD and Albumin concentration.

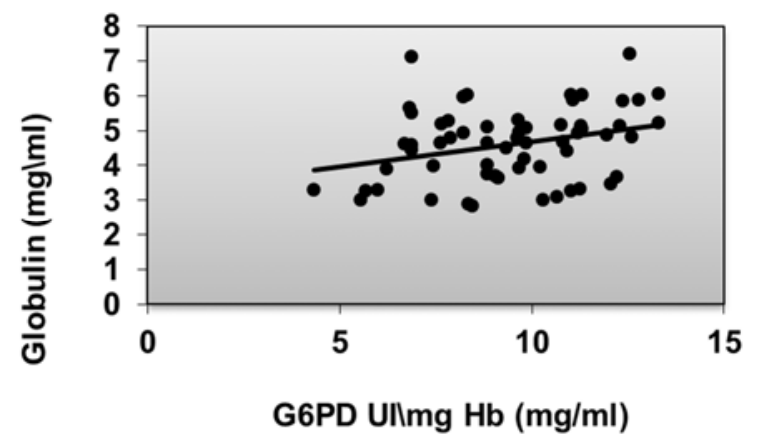

Figure 12. Correlation between G6PD and Total Globulin concentration. 
DNA was obtained from 138 samples were 68 \& 70 patients and healthy respectively (Figure 13).

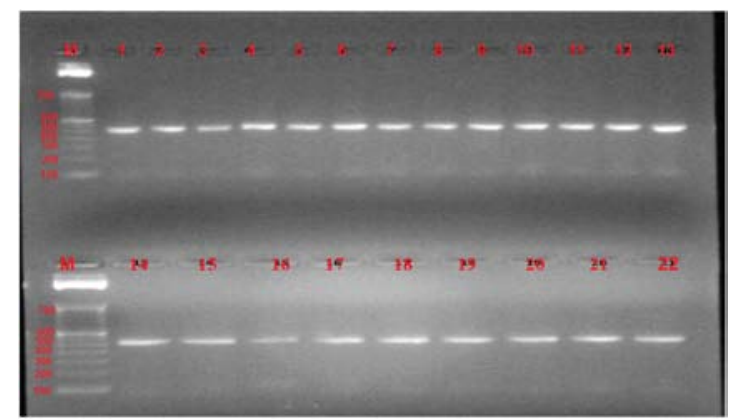

a

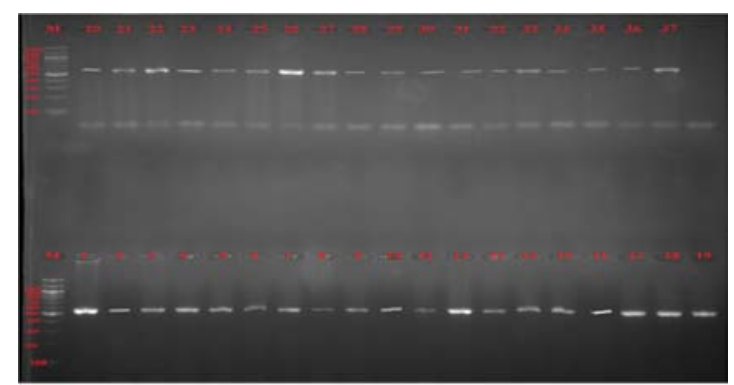

b

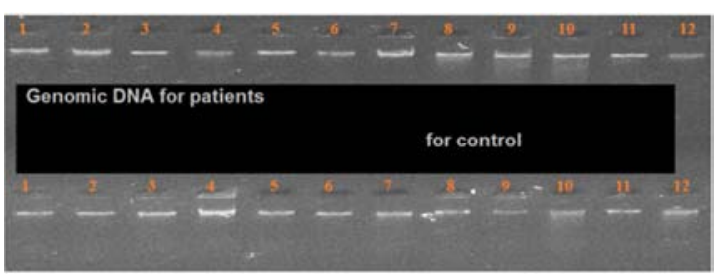

Figure 13. a- The genomic DNA on 0.8\% agarose gel, where the upper row represents the patients and the lower row control group. $b$ - PCR product of patient on $2 \%$ agarose, where the main band of the molecular weight (bp583) representing the gene G6PD. c- PCR product of the control samples on the 2\%Agrose gel. The main band shows the molecular size (bp583) representing the gene G6PD.

The results of C563T primer showed the presence of MboII, which targeted the G6PD gene sequence, which encodes G6PDH. The results were same molecular weight bands as shown as in Figures 13 and 14. The resulting bands were shown in 60 patients and 60 control group, And those that have not been shown may not be due to decreased DNA purity or concentration, and may be caused by an increase or decrease in the concentration of the primer used or the presence of another mutation at the amplified fragment, which affects initial fusion or For manual error in addition to the primer.

\section{Conclusion}

The RFLP- PCR technique is capable to detect any heterogeneity on the DNA molecule, even though this variation is at the level of a single nitrogen base. Accordingly the mutations can be identified [29].
After the PCR products were digested with restriction enzyme, the optimal concentration of the enzyme was 10 units. The PCR products was then carried out after cutting onto the $2.5 \%$ agarose gel. The Mediterranean mutation bands were $(379,24,60,120)$, and the specimens carrying the Mediterranean mutation $(24,60,103,120,276)$, as in Figures 13 and 14.
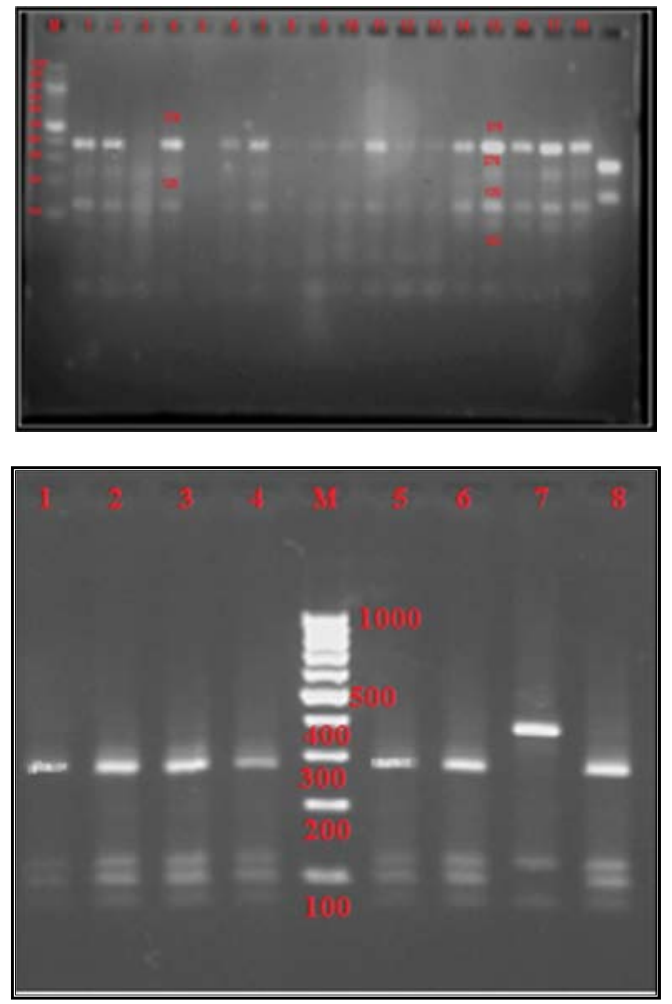

Figure 14. a- The gel electrophoresis of the PCR product of the patient samples. The Mbo II, which represents the Mediterranean mutation, appears in samples 1-6 with molecular weight 60, 103 and 120, 276bp. Sample 7 is Representing the natural sample and its molecular weight (60, 120, $379 \mathrm{bp}$, and $M)$ ) represents the $100 \mathrm{bp}$ DNA Ladder. $b$-represents the products of PCR-RFLP control group M: representing 100bp DNA Ladder Samples (1, $2,15,17,18)$ represent the Mediterranean mutation. Samples $(3-14,16)$ represent the natural pattern.

The relationship of the Mediterranean mutation to diabetes:

The results obtained in Tables (6 and 7) showed that the individuals who carried the mutation were $78.3 \%$, compared to the healthy ones who carried the mutation, which was $15 \%$. There is a significant difference in the probability level $(\mathrm{P} \leq 0.05)(21.6 \%)$. There was no significant difference at the probability level $(\mathrm{P} \leq 0.05)$ with the control group, and the control group with the mutation showed that the mutation rate in patients was higher than the control group. When comparing the group of patients with the mutation and those without the mutation, there was a significant decrease $(\mathrm{P} \leq 0.05)$ among patients with mutation of non-mutation patients. This is because the lack of enzyme efficacy in patients and healthy is due to the mutation in the enzyme gene and is often the Mediterranean mutation. This is consistent with the study of Al-Tu'ma. et al [9] The percentage of people with jaundice who have a deficiency in the effectiveness of the enzyme is the 
Mediterranean mutation (75-94\%) in five governorates of central and southern Iraq. another study by Oppenheim, A., et al. [30], and Al-Temmemy, et al, [10] who found the proportion of Iraqi samples infected with anemic deficiency that carries the Mediterranean mutation is $(95.8 \%)$ of the total number of people with anemia. Study in Iraqi Kurdistan by AlAllawi et al [31] found that the Mediterranean mutation is predominant over the rest of the mutations in the region. As well as the same researchers proved at the level of the city of Baghdad [32].

As well as a study in western Iran in which Rahimi Z, Vaisi-Raygani A, Nagel R, et al., [33] found that the percentage of enzymatic deficiency resulting from the Mediterranean mutation was $91.2 \%$, an extension of previous studies in northern and southern Iran. The common mutation is the Mediterranean. In a study by Saleh Ahmed Bin Amro, et al [34] the Mediterranean mutation is common in the UAE. The Mediterranean mutation is common in the Middle East this result found by Kurdi-Haidar, et al [35], and the correlation between the Mediterranean mutation and the high of glucose $(\mathrm{P} \leq 0.05)$, in patients compared to the group of patients who do not bear mutation indicating that the effect of the mutation at the level of sugar in patients and therefore there is a link between people who carry the mutation and the aggravation of diabetes may be linked between the mutation and the effectiveness of insulin, and this should be discussed in the future. Thus, there appears to be a correlation between the Mediterranean mutation on site T563C in the G6PD gene and the low levels of G6PDH in the blood for diabetics and therefore there is a direct or indirect effect of the Mediterranean mutation on diabetics. Tables 6 and 7 showed no significant effect at the level of probability $(\mathrm{P} \leq 0.05)$ of the mutation at the level of other biochemical variables were measured.

Table 6. Relationship between G6PD gene mutation and G6PD enzyme levels for diabetic patients.

\begin{tabular}{lll}
\hline Mutant allele & Normal allele & Type of allele for patient \\
\hline 47 & 13 & Number from 60 \\
78.3 & 21.6 & Percentages (\%) \\
$* * 8.59 \pm 1.72$ & $12.2 \pm 0.705$ & G6PD activity (UI/g Hb) \\
$* *-7.05$ & $0.0001^{* *}$ & t-test P value \\
$1.8 \pm 0.174$ & $1.84 \pm 0.238$ & Con of Mg (mg Pl) \\
0.523 & 0.83 & t-test P value \\
$8.83 \pm 1.95$ & $8.49 \pm 1.85$ & Con of Ca (mg $\backslash$ dl) \\
-1.97 & 0.052 & t-test P value \\
$272 \pm 74.1$ & $181 \pm 16.3$ & Con of glucose (mgldl) \\
\hline
\end{tabular}

Table 7. Relationship between the Mediterranean mutation of G6PD gene and G6PD enzyme levels of the control group.

\begin{tabular}{llll}
\hline Normal allele & Mutant allele & Type of allele for patient & \\
\hline 51 & 9 & sample 60Number of & \\
85 & 15 & Percentage $(\%)$ & \\
$14.2 \pm 1.77$ & $13.5 \pm 1.14$ & G6PD activity $(\mathrm{UI} \backslash \mathrm{G} \mathrm{Hb})$ & \\
1.41 & 0.16 & t-test & P value \\
$1.81 \pm 0.182$ & $1.78 \pm 0.131$ & Con of $\mathrm{Mg}(\mathrm{mg} \backslash \mathrm{dl})$ & \\
0.787 & 0.43 & t-test & P value \\
$9.49 \pm 1.36$ & $8.38 \pm 1.49$ & Con of Ca (mg $\backslash \mathrm{dl})$ & \\
0.135 & 0.89 & t-test & P value \\
$79 \pm 16.1$ & $89 \pm 19.7$ & Con of glucose (mg $\backslash \mathrm{dl})$ & \\
\hline
\end{tabular}

\section{References}

[1] WHO (2015); Definition, Diagnosis and classification of diabetes mellitus and complication. part 1: Diagnosis and classification of diabetes mellitus. Department of noncommunicable disease surveillance, Genève.

[2] American Diabetes Association, (2016). "Diagnosis and classification of diabetes mellitus," Diabetes Care, vol 33, (supplement 1): S62-S98.

[3] Patlak, M., (2002). New weapons to combat ancient treating diabetes. FASEB, J, 16 (14): 1853.

[4] Saúl Gómez-Manzo Jaime Marcial-Quino America VanoyeCarlo, Hugo Serrano-Posada, Daniel Ortega-Cuellar, Abigail González-Valdez, Rosa Angélica Castillo-Rodríguez, Beatriz Hernández-Ochoa, Edgar Sierra-Palacios, Eduardo RodríguezBustamante and Roberto Arreguin-Espinosa. (2015). (Glucose-6-Phosphate Dehydrogenase: Update and Analysis of New Mutations around the World Colombia.s 1. p 2-p 12.

[5] Beutler, E. 2011., G6PD Deficiency and other enzyme abnormalities. in.: Williams hematology. Med ctext book. edit by Beutler. lichtman, M. A. coller, B. S. and Kipps, T. J. McGraw-Hill. Newyork. chap. 45: 562-583.

[6] R. Notaro, A. Afolayan, L. Luzzatto. 2010. Human mutations in Glucose-6-phosphate Dehydrogenase reflect evolutionary history. FASEB Journal 14, p (485-494).

[7] S. Singh, A. Anand, P. K. Srivastava. (2012). Regulation and properties of glucose-6-phosphate dehydrogenase: Areview. International Journal of Plant Physiology and Biochemistry 4 (1), p (1-19).

[8] Saremi Mohammad Ali, Saremi Mahnaz and Tavallaei Mahmood. (2008). Rapid genomic DNA extraction (RGDE) Forensic Science International: Genetics Supplement Series 1. p 63-65.

[9] Al-Tu'ma. F. Jawad and William M. Frankool. (2010). Molecular Basis of G6PD Deficiency in Hyperbilirubinemic Neonates in Middle Euphrates Province: Iraq. Karbala J. Med. Vol. 3, No. 3, 4. P (867-881).

[10] Al-Jumaily Essam F. and Al-Temmemy Rana A.(2009). Identification of mediterranean mutation in the G6PD gene on molecular level in Iraqi population. Biotechnology Research Center (special edition) Vol. 3- No. p (90-99).

[11] Seri, Ali. (2013). princple of medical genetic. $2^{\text {nd }}$ edition, home of shuaa to publish and science Aleppo, Syria. page (281-295).

[12] Cappai G, Songini M, Doria A, CavalleranoJD, Lorenzi M. (2011). Increased prevalence of proliferativeretinopathy in patientswith typel diabetes who are deficient in glucose-6phosphate dehydrogenase. Diabetologia. 54: 1539-1542.

[13] Nkhoma ET, Poole C, Vannappagari V, HallSA, Beutler E. (2009). The global prevalence of glucose-6-phosphate dehydrogenase deficiency: a systematic review andmetaanalysis. Blood Cells Mol Dis; 42: 267-278.

[14] Riyadh. M. Murtadha. 2013. Is There Any Association Between Type 2 Diabetes Mellitus and Biochemical Evidence of Vitamin D Deficiency Karbala Journal of Pharmaceutical Sciences Number 6. p (147-152). 
[15] Ameerah M. Ali Al-Hassan, Reyam A. Hatif, Ruaa H Dhari and Entehaa H. Edan. 2016. Study on Diabetes Mellitus and the Balance of Electrolytes. Journal of Babylon University/Pure and Applied Sciences/ No. (7)/ Vol. (24). P (1947-1953).

[16] Crawford A, Harris H. 2012. Balancing act: calcium \& phosphorus [J]. Nursing, 42 (1): 36-42.

[17] Hamad NA, Eltayeb LB, Brair SL, Bakheit KH, Hamdan ZK, Omer WH: (2013), a clinical study of serum calcium, phosphorus, Alkaline Phosphatase and Magnesium level in type II Diabetes mellitus among Sudanese population in Khartoum state; Al Neelain in Medical Journal, 3 [10]; 42-50.

[18] Levy J, Zhu Z, Dunbar JC. (1998). The effect of glucose and calcium on $\mathrm{Ca}^{2+}$-adenosine tri phosphatasein pancreatic islets isolated from a normal and a non-insulin-dependent diabetes mellitus rat model. Metabolism. Feb; 47 (2): 185-9.

[19] Fogh-Andersen N, McNair P, Muller-Petersen J and Madsbad S. (2011). Serum calcium fractions in diabetes mellitus. American Association Journal for Clinical Chemistry. 28: 2073-2076.

[20] AL-Sammraie Abdilkarim. J. Yehia. (2015). Evaluation of Vitamin D Status in Patients with Type 1 Diabetes Mellitus Al-Mustansiriyah Journal of Science Vol. 26, No 1,. P (15-18).

[21] FANG Linyan, LI Xueping. 2016. Level of serum phosphorus and adult type 2 diabetes mellitus [J]. Journal of Central South University. Medical Science, 41 (5): 502-506.

[22] Sung, C. C., Liao, M. T., Lu, K. C., \& Wu, C. C. (2012). Role of vitamin $\mathrm{D}$ in insulin resistance. BioMed Research International., 357. p: 266-282.

[23] Noori-Daloii, M. R., et al. (2007)., A comprehensive study on the major mutations in glucose-6-phosphate dehydrogenase deficient polymorphic variants identified in the coastal provinces of Caspian Sea in the north of Iran. ClinBiochem. 40 (9-10): p. 699-704.

[24] Salim J. Khalaf. 2010." Study of some biochemical markers in diabetic patients. Tikrit Medical Journal. 16 (2): 84-87.

[25] Nanda, R., Mishra, P. K., Das, U. K., Rout, S. B and panda, A. 2014. Evaluating role of oxidative stress in determining the pathogenesis of Flaciparium malaria induced acute renal failure. Indian J. Clin. Biochem. 19 (1): 93 - 96.

[26] Ou HY, Yang YC, Wu HT, Wu JS, Lu FH, and Chang CJ. 2011.: Serum fetuin-A concentrations are elevated in subjects with impaired glucose tolerance and newly diagnosed type 2 diabetes. Clin Endocrinol (Oxf).; 75 (4): 450-455.

[27] Amal R. Farahan and Walla E. Jassem. 2015. The Effect of Age and Gender on Fetuin-A and Some Biochemical parameters in Blood Sera of Iraqi patients with T2DM: A comparative study. Baghdad Science Journal Vol. 12 (1). p (197-203).

[28] Pinna Antonio et, al.(2011). glucose-6-phosphate dehydrogenase deficiency and diabetes mellitus with severe retinal complications in Sardinian population, Italy. International journal of medical science, vol 10 (13), 1907-1913.
[29] Mandel, J. L.; Monaco, A. P.; Nilson, D. L.; Schlessinger, D. and Willerd, H. (1992). Genome Analysis and the Human X chromosome. Science 258: 103-109.

[30] Oppenheim, A., et al. (2013). G6PD Mediterranean accounts for the high prevalence of G6PD deficiency in Kurdish Jews. Hum Genet, 91 (3): p. 293-4.

[31] Al-Allawi N, Eissa AA, Jubrael JMS, Jamal SAR, Hamamy H. 2010. Prevalence and Molecular Characterization of Glucose-6-Phosphate Dehydrogenase Deficient Variants among the Kurdish population of Northern Iraq. BMC Blood Disorders, 10: 6.

[32] Al-Hamamy H. A, Th. Kh. Saeed, Alwan. A. S. March 2011. Association of Glucose-6-Phosphate Dehydrogenase Deficiency with Diabetes Mellitus. journal of clinical Volume 2, Issue 2. Pages 110-112.

[33] Rahimi, Z., et al. 2016. Molecular characterization of glucose6-phosphate dehydrogenase deficiency in the Kurdish population of Western Iran. Blood Cells Mol Dis, 37 (2): p. 466. Mesbah-Namin, S. A., et al. (2012). Three major glucose6-phosphate dehydrogenase-deficient polymorphic variants identified in Mazandaran state of Iran. Br J Haematol, 117 (3): p. 763-4.

[34] Saleh Ahmed Bin Amro, Eiman Al Zaabi, Shakir Hussain, Amira Mahmoud Aly, Huda Salman Baqir, Abdul-Hamid Ahmed Zaki, Sultan Ayesh Mohammed Saghir and Narazah Mohammed Yusoff. 2014. Molecular Characterization of Glucose-6-Phosphate Dehydrogenase Deficiency in Abu Dhabi District, United Arab Emirates. Tropical Journal of Pharmaceutical Research 13 (5): 731-737.

[35] Kurdi-Haidar B, Mason PJ, Berrebi A, et al. (2012). Origin andspread of the glucose-6-hosphate dehydrogenasevariant (G6PD-Mediterranean) in the Middle East. Am J Hum Genet; 47 (6): 1013-9.

[36] Tishkoff, S. A., et al. (2011). Haplotype diversity and linkage disequilibrium at human G6PD: recent origin of alleles That confer malarial resistance. Science. 293 (5529): p. 455-462.

[37] Cappellini MD, Fiorelli G (2008) Glucose 6-phosphate dehydrogenase deficiency. Lancet: 371: 64-74.

[38] Drousiotou, A.; Lefranc, G.; Helal, A. N.; Loiselet, J. and Tishkoff, S. A. (2012). Evidence for balancing selection from nucleotide sequence analyses of human G6PD. Am. J. Hum. Genet, 71: 1112-1128.

[39] Trask, B. J.; Massa, H.; Kenwrick, S. and Gitschier, J., Am. J. 1991. Hum. Genet. 48, 1-15.

[40] Persico, M.; Viglietto, G.; Martini, G., Toniolo, D.; Paonessa, G. and Moscatelli, C. (2011). Nucleic Acid Res. 14, 2511-22.

[41] Marwa. A. T. (Nov, 2015); Evaluation of Calcium, Phosphorus and Magnesium Level Among Vitamin (D) Deficient Diabetes Mellitus Patients in Khartoum State Sch. Bull.; Vol-1, Iss-9. 235-241. 